\title{
Solving for Inclusive Technology for Older Adults
}

\author{
By J. Alison Bryant and Patty David
}

y 2030, more than a quarter (27.3 percent)

of the world's population will be ages 50 and older (16.5 percent will be ages 60 and older). ${ }^{1}$ For the first time in history, the older population will outnumber the younger population. As our AARP CEO Jo Ann Jenkins said at the 2020 Consumer Electronics Show, "All businesses and entrepreneurs need to recognize the growing economic power and potential of the 50-plus market and help create innovative solutions to empower us to live better as we age.... [O]ur growing older population is driving $\$ 8.3$ trillion of economic activity a year, along with innovation and new value creation."

Many of the innovative solutions and opportunities to capture this growing market of age 50-plus consumers are driven by (or at the very least include) technology. According to The Longevity Economy Outlook , a new AARP report that looks at the overall economic contribution of older adults, 50 -plus spent an estimated $\$ 140$ billion on technology in 2018 and this spending is forecasted to reach $\$ 645$ billion by 2050 .

Being able to access and effectively use technology has become critical for almost every aspect of life: we need it to work, connect socially, access health care information, and just generally make life easier. Technology is no longer a nice to have; it's a must have.

\section{Current Tech Use for US Adults Ages 50-Plus}

In the United States, older adults are recognizing this necessity. Recent AARP research on consumer technology adoption shows that 9 in 10 adults over age 50 own a computer [see Figure 1]. ${ }^{2}$ Mobile device adoption also continues to trend upward: nearly 8 in 10 older adults own a

Device Adoption Among Those Ages 50-59 ( $n=972), 60-69(n=849)$, and 70 and Older $(n=776)$

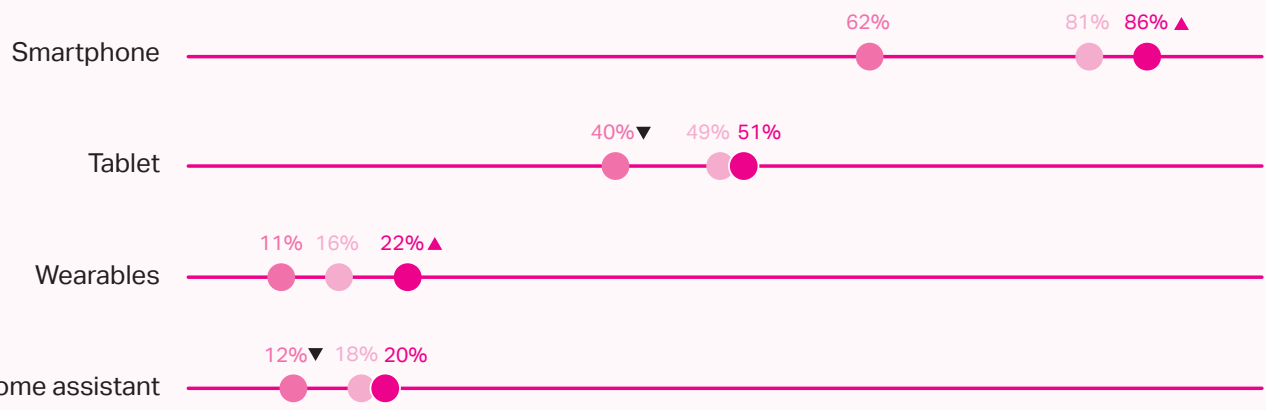

Smart home Technology
Base: Total Respondents ( $\mathrm{n}=2,607)$
Q. TECH1 Which of the following items do you have? 


\section{By cogently addressing these five barriers, we hope that tech companies, retailers, entrepreneurs, and others in this space will find ways to both benefit the older population and increase market opportunities.}

smartphone, and adults ages 50 -plus have now surpassed their younger counterparts in tablet ownership. Emerging markets such as home and health tech are also of interest to older consumers. Despite being slightly later adopters of many devices, these individuals are testing out newer tech such as wearables, home assistants, and smart home technology at near parity with younger generations.

But the 50-plus market is not a monolith. Age is a big differentiator in overall adoption and usage rates. While those in their 50 s are playing games daily, checking Facebook, and managing their finances online, adults over age 70 are less likely to even have smart tech - and they are less likely to engage with it if they do.

\section{Breaking Down the Tech Barriers}

When it comes to the adoption and use of technology by older adults, we've seen a disconnect between their desire to leverage new platforms, apps, and services, and their actual use of this technology. Much of that disconnect can be understood by looking at five key barriers to technology adoption, which we have identified based on several years of research and engagement with consumers. By cogently addressing these five barriers, we hope that tech companies, retailers, entrepreneurs, and others in this space will find ways to both benefit the older population and increase market opportunities.
The five barriers to older-adult tech adoption are the following [see Figure 2]:

- Design and User Experience (UX) - Whether technology has been designed with older adults in mind and as part of the design process

- Awareness and Interest - Whether older adults know about new tech and think that it is relevant to them

- Cost and Acquisition - Older adults' ability to get and pay for devices or services

- Installation and Adoption - Challenges to setting up a device or service, or making it part of one's daily life

- Trust and Privacy - Concerns about whether one's data and information are secure

In addition to these barriers, there is an underlying need and opportunity for more lifelong, ongoing digital literacy efforts; this way, consumers will feel empowered when it comes to engaging with technology. We have to come at these problems from both angles: give consumers something that is designed for them and considers their needs/wants, and also empowers them to use it and to have a voice in the marketplace.

If we look internationally, we see great examples of countries trying to address the digital literacy issue. For example, Mauritius has developed a model that offers a cost-effective 


\section{In many - or most - cases, taking a more inclusive design approach will not only mitigate these barriers for older adults but also improve the experience for younger users.}

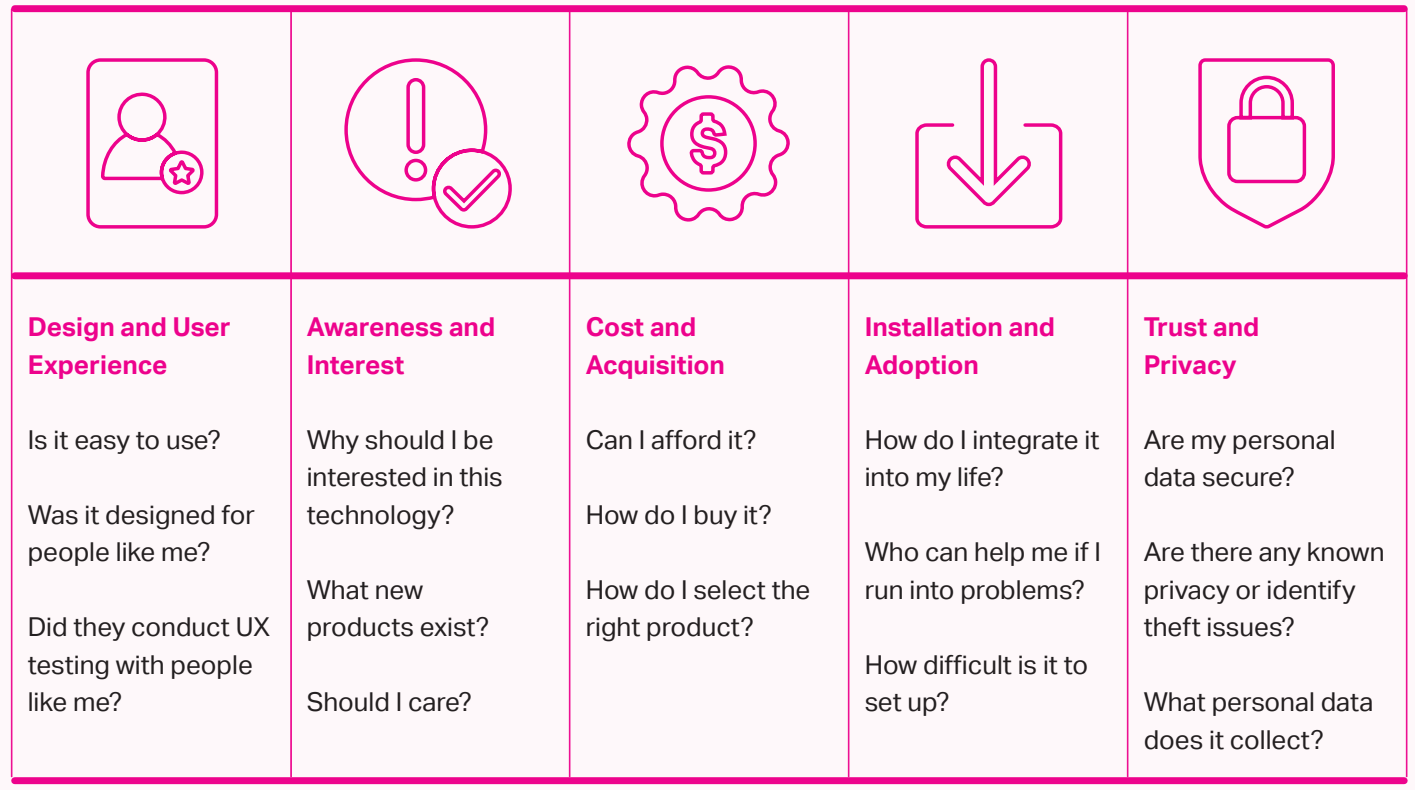

Figure 2. Barriers to technology for older adults 
approach to digital literacy training in rural or geographically isolated areas. ${ }^{3}$ In that country's Cyber Caravans program, computer-equipped and Internet-connected buses bring technology to underserved communities, including those of older adults. Similarly, Lebanon's University for Seniors offers in-depth technology training courses specifically created for the older population. ${ }^{3}$

As for corporate efforts, global consumer electronics company Samsung recently announced it will be focusing on "inclusive design" to address the needs of older adults. ${ }^{4}$ In general, however, there have not been widespread efforts to address these barriers from the tech and retail industries as they develop, market, and sell their products.

Therefore, solutions to address these barriers will require cross-industry and cross-sector collaboration, and may take the forms of new platforms, technological innovations, policies, services, or programs. The good news is that, as with so many age-friendly solutions (e.g., the universal design that exists in livable communities), everyone benefits. In many — or most — cases, taking a more inclusive design approach will not only mitigate these barriers for older adults but also improve the experience for younger users. And that is what we really need: technology that is designed for all, with experiences customizable by individuals to suit their needs.

So, what are some first steps that we can take on the path to inclusive design? The most important thing is to include older adults from the start — that is, in the design process, and even product ideation. Consider them when developing use cases. Include them when conducting UX testing. Assess them when conducting market forecasting. The more older adults are included throughout the research and design (R\&D), design, marketing, and distribution phases of products, services, and programs, the more we will inherently build more inclusive, impactful, and successful solutions and innovative offerings for the global marketplace.
1 "World Population Prospects 2019," United Nations, custom data acquired via website, https://population.un.org/wpp/. Accessed March 1, 2020.

${ }^{2}$ Brittne Nelson Kakulla, 2020 Tech Trends of the $50+$ (Washington, DC: AARP, 2020), https://doi.org/10.26419/res.00329.001. Accessed March 1, 2020.

${ }^{3}$ The Aging Readiness \& Competitiveness Initiative, AARP Aging Readiness and Competitiveness Report. AARP (Washington, DC: 2018), http://arc.aarpinternational.org/. Accessed March 1, 2020.

${ }^{4}$ WARC, "Samsung Looks to 'Inclusive Design' to Reach Boomers," January 29, 2020, https://www.warc.com/newsandopinion/news/ samsung-looks-to-inclusive-design-to-reach-boomers/43166. Accessed March 1, 2020.

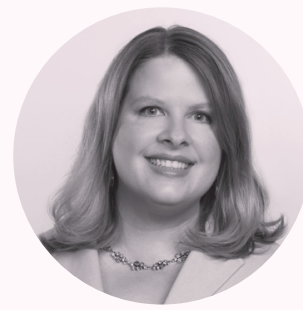

\section{J. Alison Bryant}

Senior Vice President Research AARP

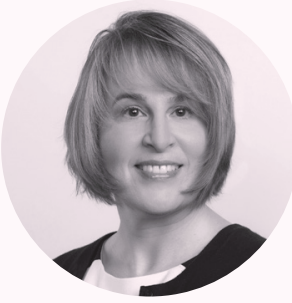

Patty David

Director

Consumer Insights AARP 